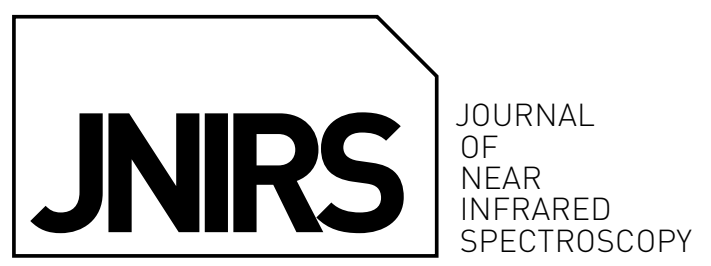

Special Issue on Milk and Milk Products

\title{
Quantification of casein fractions and of some of their genetic variants in phosphate buffer by near infrared spectroscopy
}

\author{
Laura Marinoni, ${ }^{a}$ Lucia Monti, ${ }^{b}$ Stefania Barzaghib and Begoña de la Roza-Delgado ${ }^{c}$ \\ anniversità degli Studi di Milano, DeFENS-Department of Food, Environmental and Nutritional Sciences, Division of Human Nutrition, \\ Via Celoria 2, 20133 Milan, Italy. E-mail: Laura.marinoni1@unimi.it

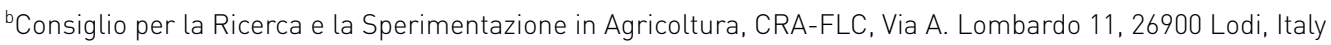 \\ ${ }^{\mathrm{c} A n i m a l}$ Nutrition Grassland and Forages, Regional Institute for Research and Agro-Food Development, Apdo. 13, 33300 Villaviciosa, Spain
}

\begin{abstract}
Milk casein and casein fraction contents have a great influence on milk rennet properties and cheese yield so that the selection of dairy cattle with genetic characteristics suitable for milk transformation is of great interest to dairy farms and firms. The possibility of a rapid and accurate determination of these parameters would be very useful to predict milk aptitude to cheese making. This work aimed to determine casein fractions and their genetic variants content using near infrared (NIR) spectroscopy in reconstituted casein samples by comparing the performance of different NIR equipment la monochromator instrument and a Fourier transform instrument) and different modes of measurement (reflectance and transflectance) in order to evaluate the best operative conditions for this application. Fifty-eight raw milk samples, collected from different farms in the Asturias region, Spain, were analysed for protein (TP\%) and non caseinic nitrogen ( $N C N \%$ ) content using the Kjeldahl method. Casein content was calculated as the difference between TP and NCN content. Casein fractions $\left(\alpha_{s 0^{-}}, \alpha_{s 1^{-}}, \alpha_{s 2^{-}}, \kappa\right.$-casein) and genetic variants of $\beta$-casein ( $\beta B-\beta A 1-, \beta A 2$-casein) were determined by a capillary electrophoresis system. Samples were ultra-centrifuged to obtain native casein and then reconstituted in phosphate buffer $(\mathrm{pH}=6.8)$ at the same original milk concentration, previously determined by the Kjeldahl method. Spectra were collected at $37^{\circ} \mathrm{C}$ with a FT-NIR instrument in transflectance mode and a monochrometer in both transflectance and reflectance mode. Partial least square (PLS) analyses performed on transflectance spectra showed good prediction ability for all variables $-\left(\min R^{2}=0.80\right.$ for $\kappa$-casein; $\max$ $R^{2}=0.94$ for $\beta A 2$-casein), with the exception of $\alpha_{\mathrm{s} 2}$-casein. NIR spectroscopy has the ability to determine and quantify casein genetic variants and could be used to select milk for its final purpose and to predict the aptitude of milk to cheese-making.
\end{abstract}

Keywords: casein fractions; casein genetic variants, Kjeldahl, NIR spectroscopy

\section{Introduction}

Caseins are the predominant milk protein compounds of almost all mammalian species, with nutritional and technological roles. ${ }^{1,2}$ Caseins from milk of ruminants have been extensively studied and have been shown to consist of four main fractions; $\alpha_{\mathrm{s} 1^{-}}, \alpha_{\mathrm{s} 2^{-}}, \beta$ - and $\kappa$-casein.

In Italian Holsteins' milk, Comin et al. ${ }^{3}$ found that $\kappa$-casein and $\beta$-casein were strongly associated with milk coagulation traits and milk and protein yields, respectively. The $\alpha_{\mathrm{s} 1}$ - and $\alpha_{\mathrm{s} 2}$-caseins strongly bind calcium which is involved in the coagulation process and the $\alpha_{\mathrm{s} 2}{ }^{-}$and $\beta$-caseins are susceptible to the proteolytic activity of plasmin, playing an important role in the ripening and flavour development of certain cheeses. Furthermore, residual rennet in cheese hydrolyses $\alpha_{s 1}$ - casein to $\alpha_{s 1^{-1}}$ casein which leads to a desirable soft texture in some aged cheeses. ${ }^{4}$ 
Caseins are heterogeneous proteins characterised by genetic polymorphism and post-translational modifications. An important post translational modification of caseins is phosphorylation, i.e. the presence of phosphate groups bound to different aminoacidic residues. For example, $\alpha_{s 1}$-casein consists of one major and one minor component, both with the same amino acid sequence; the minor component known as $\alpha_{s 0}$-casein contains one additional phosphate group linked to the serine at position 41. Due to their strong calcium bonding properties, such groups are important for both the nutritional value of milk and for the physico-chemical properties of the casein micelles. ${ }^{5}$

The polymorphism results in the presence of many genetic forms of the same protein that differ from each other for the replacement or deletion of certain amino acids within the polypeptide chain. Individuals can produce a certain protein in a single variant (homozygous) or a mixture of the two variants (heterozygous). The frequency of genetic variants of each protein varies with the animal species and the breed. ${ }^{6}$

The polymorphism of milk proteins determines differences in the molecular structure of the proteins that, in turn, lead to differences in their physico-chemical and biological properties, influencing the composition and the technological characteristics of milk and, consequently, the cheese yield. ${ }^{1}$ For these reasons, studies on milk protein genetic variability started about 50 years ago and, nowadays, it is well known that $\alpha_{s 1}$ - casein shows eight genetic variants $(A, B, C, D, E, F, G, H)$, of which $B$ is the most frequent in bovine milk and $\alpha_{s 2}$ - casein has four variants $(A, B, C, D)$ of which only $A$ and $D$ are typically found in bovine milk. ${ }^{7} \beta$-casein shows nine variants (A1, $A 2$, $A 3, B, C, D, E, F, G, H, I$ ), with $A 1$ and $A 2$ the most common; it is well known that milk characterised by the presence of the $\beta$-casein $B$ is more sensitive to the action of rennet as it tends to coagulate in a shorter time and give rise to a more consistent gel. ${ }^{1,4}$ For $\kappa$-casein, 12 genetic variants ( $A, B, B 2, C$, $E, F 1, F 2, G 1, G 2, H, I, J)$ have been found, but $A$ and $B$ are the most frequent. ${ }^{7}$

Casein polymorphisms are also involved in human nutrition, since most milk proteins are potential allergens. ${ }^{8}$ Besides, dietary proteins provide a source of biologically active peptides, i.e. specific protein fragments that have a positive effect on body functions or conditions and might ultimately influence health. ${ }^{9} \beta A 1$-casein is associated with the release of $\beta$-casomorphin- 7 , which has opioid properties resulting in an immune suppressant influence most probably implicated in the etiology of type 1 diabetes. Among biopeptides, phosphopeptides are peptides known to exert an effect on calcium metabolism. ${ }^{10,11}$

Traditional techniques for casein determination, such as electrophoretic techniques, high-performance liquid chromatography (HPLC) and mass spectrometry, are expensive and time- and solvent consuming. ${ }^{1}$ Thus, the possibility of a rapid and accurate determination of the concentration of milk casein fractions and genetic variants would be very useful for selecting milk for its final purpose and to predict milk aptitude to cheese making.
In the literature, there are many reports on the application of near infrared (NIR) spectroscopy for the prediction of milk composition, ${ }^{12-16}$ while studies on the quantification of single casein sub-fractions are limited.

In this context, the aim of the work reported here was to gain an appreciation of the potential of spectroscopic techniques when applied to the dairy sector, in particular to verify the ability of NIR spectroscopy in predicting the concentration of milk casein fractions and genetic variants in casein solutions. The work also aimed to test different instruments and optical geometries in order to assess the optimal operative conditions. In particular, two types of NIR instrumentation were compared, a monochromator and a Fourier transform (FT)-NIR apparatus. This latter instrument shows well known advantages over monochromator systems, ${ }^{17}$ even if Williams and Norris ${ }^{18}$ stated that these advantages are mainly in the mid-IR region rather than in the NIR range. As well, we aimed to investigate if the extended range of NIR monochromator could compensate for the advantages of FT technology. Two different sample presentation modes, reflection and transflection, were also compared. Reflection acquisition is the most appropriate to analyse turbid and heterogeneous liquid samples, such as casein in phosphate buffer. Transflection mode can be used for both clear and turbid liquids and, in addition, has the advantage of a high absorbance due to the light beam passing through the same sample in both directions. ${ }^{17}$

\section{Materials and methods Samples}

Raw milk samples ( $n=58$ ) were collected from different farms in the Asturias region of Spain during a one month period. After their collection, samples were kept at $4 \pm 1^{\circ} \mathrm{C}$ until their arrival at the laboratory and analysed within 24 hours.

\section{Preparation of reconstituted casein samples}

Milk samples were ultra-centrifuged at $100,000 \mathrm{~g}$ for $1 \mathrm{~h}$ at $4 \pm 1^{\circ} \mathrm{C}$ in order to obtain the native casein by sedimentation. Caseins were then reconstituted to their initial concentration in milk by diluting the centrifuged samples in adequate amounts of phosphate buffer, PBS $0.1 \mathrm{M}$, at pH $=6.8$ [di-sodium hydrogen ortophosphate anhydrous, 98\% (Carlo Erba, Italy) dissolved in distilled water; $\mathrm{pH}$ was adjusted by adding phosphoric acid, 99\% (Sigma-Aldrich, St Louis, MO, USA)], as shown in Figure 1. Casein content, ranging from $2.40 \%$ and $2.90 \%$, was calculated as the difference between total protein and non-caseinic nitrogen content determined by the Kjeldahl method. ${ }^{19,20}$

\section{Electrophoretic analyses}

Capillary zone electrophoresis (CZE) analyses were carried out on reconstituted samples, as reported by Recio ${ }^{21}$ with a Beckman P/ACE MDQ apparatus (Beckman Coulter Srl, Milan, Italyl equipped with an UV detector and a temperature-controlled capillary compartment. 


\author{
Whole milk \\ Natural surface skimming \\ Centrifugation \\ $\left(100000 \mathrm{~g}\right.$ for 1 hour at $4 \pm 1^{\circ} \mathrm{C}$ ) \\ Supernatant removal \\ Freeze drying of native casein \\ Reconstitution in phosphate buffer \\ $(0.1 \mathrm{M}, \mathrm{pH}=6.8)$
}

Figure 1. Flow chart of the preparation of reconstituted casein samples.

Separations were performed under denaturant conditions using a coated fused-silica capillary (Beckman Instruments, Fullerton, CA, USA) of $60 \mathrm{~cm} \times 50 \mu \mathrm{m} \mathrm{ID}(50 \mathrm{~cm}$ to the detector window). Sample solutions were injected for $5 \mathrm{~s}$ at $0.5 \mathrm{psi}$ and separations were performed at $38 \pm 1^{\circ} \mathrm{C}$ by applying a constant $25 \mathrm{kV}$ voltage. UV-detection was performed at $214 \mathrm{~nm}$ and electropherograms were recorded with 32 Karat software version 7.0 (Beckman Coulter Srl, Milan, Italy). Each sample was analysed in duplicate and the average of the normalised area (=area/migration time) of each peak was calculated.

\section{Near infrared spectroscopy and statistical analyses}

Reconstituted casein solutions were kept in a bath at $37 \pm 1^{\circ} \mathrm{C}$ for $30 \mathrm{~min}$ before analysis. Spectra were then collected with two spectrometers, a FT-NIR spectrometer Spectrum One (Perkin-Elmer, Waltham Massachusetts, USA) and a FossNIRSystemsTM 6500 scanning monochromator (Foss, Hillerød, Denmark). FT-NIR analysis was performed in duplicate in transflectance mode $\left(1112-2500 \mathrm{~nm}\right.$; resolution $=4 \mathrm{~cm}^{-1}$; scan time $=31 \mathrm{~s}$ ), using a transflectance accessory with $0.25 \mathrm{~mm}$ thickness [Figure 2(a)]. Each spectrum was averaged from 30 scans. The Foss-NIRSystems 6500 instrument was equipped with a transport module and spectra $(400-2500 \mathrm{~nm})$ were collected from two sub-samples. The first sub-sample was placed in a $50 \mathrm{~mm}$ diameter gold transflectance cell, with $0.1 \mathrm{~mm}$ sample thickness cam-lock cell [Figure 2(b)] and scanned at $2 \mathrm{~nm}$ intervals. The second sub-sample was analysed in reflectance mode with an opaque liquid cell [Figure 2(c)]. In both cases, samples were analysed in duplicate and each spectrum was averaged from 32 scans. Spectra were collected at $37 \pm 1^{\circ} \mathrm{C}$ thanks to the temperature control system of the instrument.

Data were processed by Matlab R2009a (The Mathworks Inc., Natick, MA, USA) and PLS Toolbox 5.8 (Egenvector, Manson, WA, USA).

Regressions between electrophoresis values and spectral data were computed by partial least square (PLS) regression. Within the whole data set, 20 samples were set aside to test prediction while the remaining 38 were used to develop calibration models.

Calibration models were evaluated on the basis of five parameters: the coefficient of determination $\left(R^{2}\right)$; the root mean square error of prediction (RMSEP); the coefficient of variation ( $C V \%)$; the the ratio error range (RER), calculated as the ratio of the range of the reference values divided by the standard error of prediction (SEP); the ratio of the standard deviation (RPD) of the reference values divided by the SEP. These two latter parameters were used to classify the success of the predictive models using the criteria described by Williams. $^{22}$

\section{Results and discussion Casein fractions content}

Due to the complex matrix of milk, ${ }^{1}$ this work was carried out on a simplified model, in order to focus the attention only on the caseinic portion, but maintaining the same properties and proportions present in milk (solution state, $\mathrm{pH}$ and casein concentration on the basis of the Kjeldahl results).

The electrophoretic analysis performed on samples of reconstituted casein allowed the separation of the different
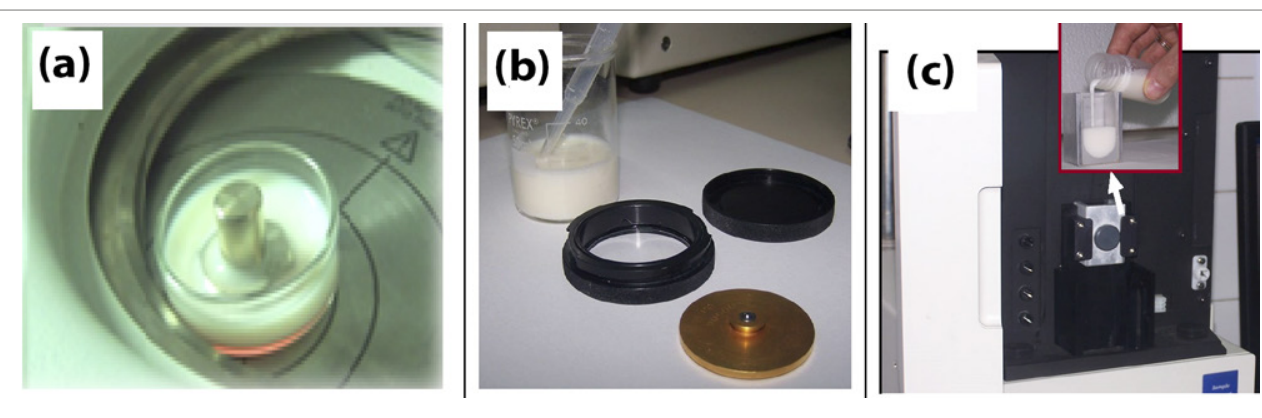

Figure 2. Transflectance accessory for FT-NIR analysis (a), gold transflectance cell (b) and opaque liquid cell (c) for NIR monochromator reflectance analyses. 


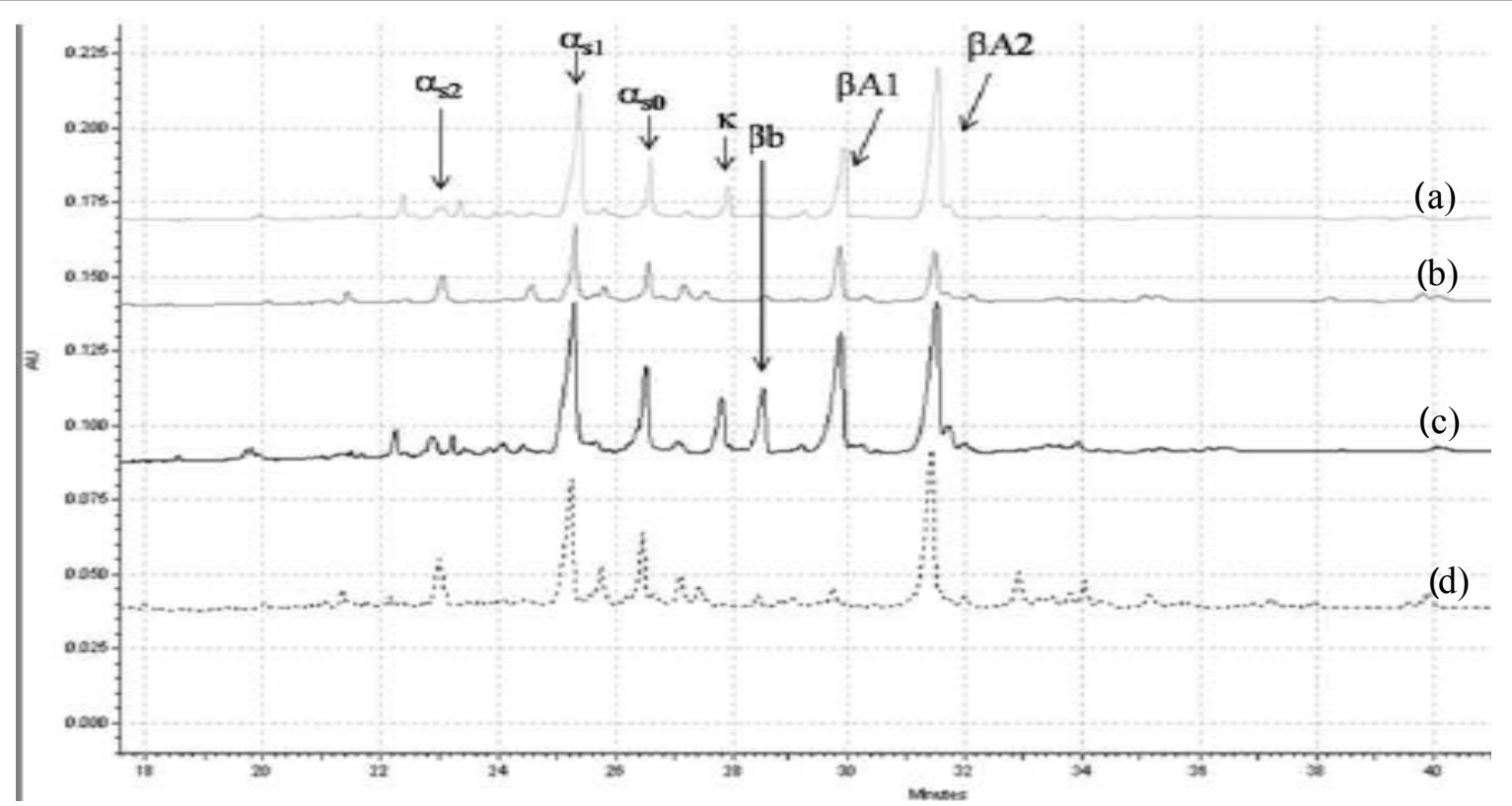

Figure 3. Examples of four casein reconstituted samples (a), (b), (c) and (d) with different electrophoretic patterns.

casein fractions: $\alpha_{\mathrm{s}^{-}}, \alpha_{\mathrm{s}^{-}}, \alpha_{\mathrm{s} 0^{-}}, \kappa^{-}, \beta \mathrm{B}-, \beta \mathrm{A} 1$ - and $\beta \mathrm{A} 2$-caseins. Figure 3 shows some examples of the electrophoretic profiles of the casein reconstituted samples. Peaks were identified by comparing the electropherograms of standard proteins with those from previous works. ${ }^{23}$

The obtained results, expressed as normalised area (area/migration time), are shown in Figure 4.

This boxplot highlights the great variability for the $\alpha_{\mathrm{s} 1^{-}}, \beta A 1-$ and $\beta A 2$-casein fractions. Conversely, $\alpha_{s 0^{-}}, \alpha_{s 2^{-}}, \kappa-, \beta B$-caseins were present in low amounts and were characterised by less variability.

\section{NIR spectra}

Figures 5(a), (b) and (c) show NIR mean spectra, after absorbance conversion, of reconstituted native casein samples obtained with the two different instruments and two different sample presentation modes.

All spectra were characterised by the strong absorption bands related to water, at $1450 \mathrm{~nm}$ and $1940 \mathrm{~nm}$, representing the $\mathrm{O}-\mathrm{H}$ first overtone stretching and the $\mathrm{O}-\mathrm{H}$ second overtone bending, respectively. ${ }^{18}$ The recognition of absorption bands related to the other components was possible only when the $2^{\text {nd }}$ derivative was applied as a pre-treatment [Figures 5(d), (e) and (f)].

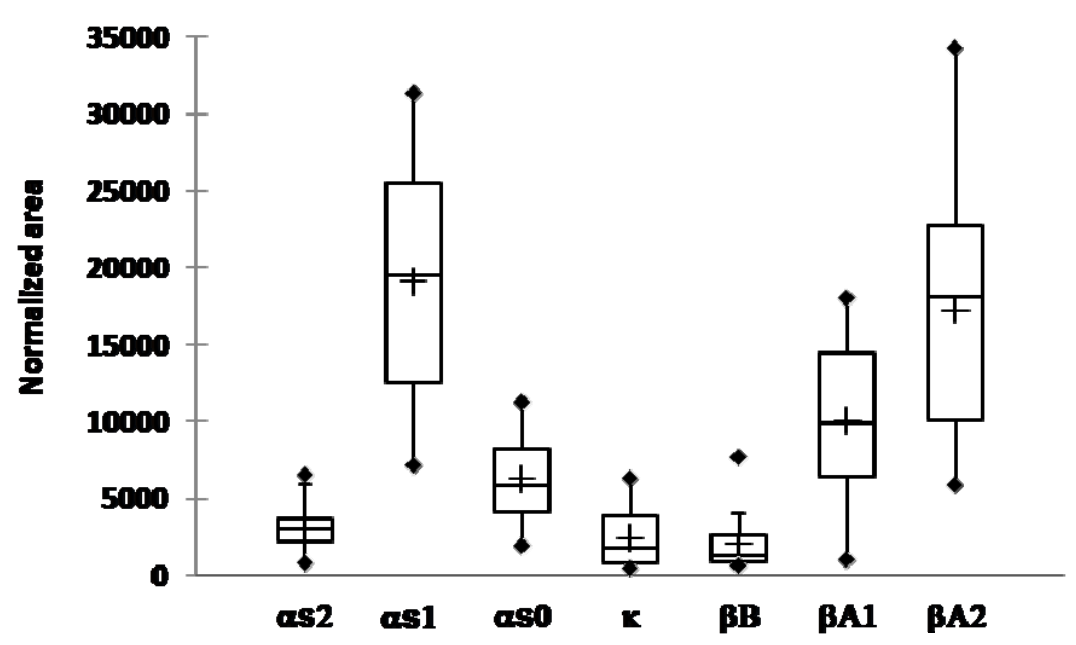

Figure 4. Box plot representation of casein fractions content in reconstituted samples. Line in the centre of the rectangular box represents the median, cross represents the mean value and diamonds indicates the maximum and minimum values of the data set. 

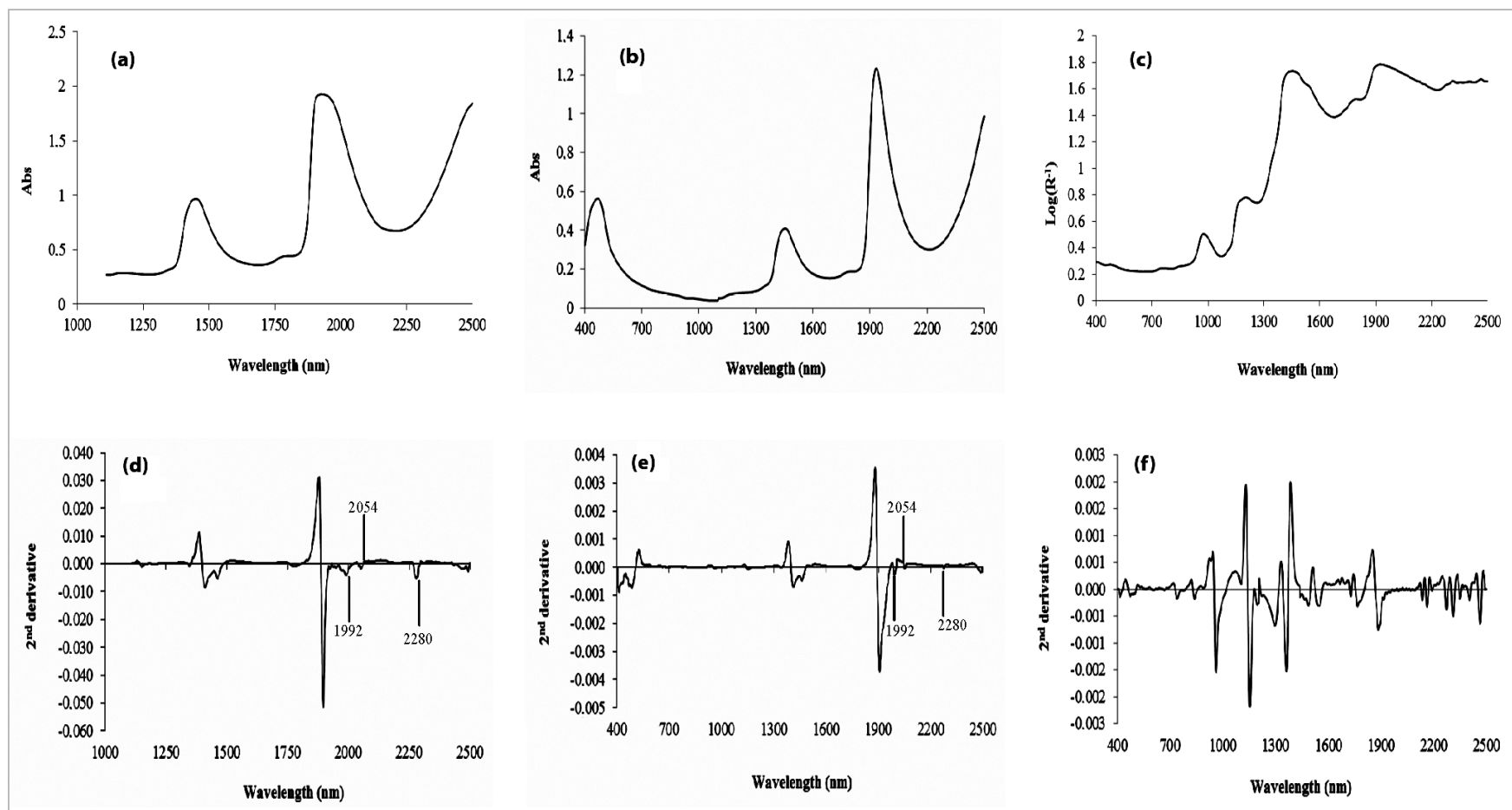

Figure 5. NIR mean spectra (a), (b) and (c) and their corresponding second derivative (d), (e) and ( $f$ ) of reconstituted casein obtained in transflectance mode with the Perkin-Elmer FT-NIR (a) and (d) and with the Foss-NIRSystem 6500 (b) and (e); in reflectance mode with the Foss-NIRSystem 6500 (c) and (f).

Noticeable spectral features in the second derivative spectra collected in transflectance [Figures 5(d) and 5(e)] occurred at $1992 \mathrm{~nm}, 2054 \mathrm{~nm}$ and $2280 \mathrm{~nm}$ due to absorption by the $\mathrm{NH}$ of protein. $^{12,17}$

The second derivative spectrum collected in reflectance [Figure 5(f)] was more informative. Spectral bands ascribable to changes in phosphate and water could be identified between $1280 \mathrm{~nm}$ and $1880 \mathrm{~nm}$ (P-OH stretching). ${ }^{18}$ Signal recorded at $2120 \mathrm{~nm}$ is due to $\mathrm{N}-\mathrm{H}$ stretching $+\mathrm{C}=0$ stretching of amino acids; that at $2160 \mathrm{~nm}$ is the combination band of amide I and amide III; at $2260 \mathrm{~nm} \mathrm{~N}-\mathrm{H}$ stretching $+\mathrm{NH}_{3}$ deformation of amino acids occur; $2300 \mathrm{~nm} \mathrm{N-H}$ stretching $+\mathrm{C}-\mathrm{H}$ deformation of amino acids. In the short wave range, the absorptions at
$750 \mathrm{~nm}$ and $860 \mathrm{~nm}$ could be associated with the $\mathrm{N}-\mathrm{H}$ third overtone bands of proteins, as reported by Tsenkova et al. ${ }^{24}$ The peak at $952 \mathrm{~nm}$, being very close to the water band, was probably connected with the influence of water-soluble protein of milk on water absorption. ${ }^{24}$ The spectral features around $1140 \mathrm{~nm}$ could also be attributed to the absorption by proteins. ${ }^{12}$

\section{PLS calibration models}

PLS analyses were performed with all NIR spectra collected from the three spectral acquisition methods and electrophoretic data. Sample characteristics for calibration and validation sets are reported in Table 1. Table 2 shows the

Table 1. CZE data for samples in the calibration and the validation sets. Values are expressed as normalised areas.

\begin{tabular}{|c|c|c|c|c|c|c|c|c|}
\hline \multirow{2}{*}{ Variable } & \multicolumn{4}{|c|}{ Calibration set } & \multicolumn{4}{c|}{ Validation set } \\
\cline { 2 - 9 } & Min & Max & Mean & STD & Min & Max & Mean & STD \\
\hline$\alpha_{\mathrm{s} 2}$ & 767 & 5896 & 3085 & 1135 & 815 & 6507 & 3020 & 1679 \\
\hline$\alpha_{\mathrm{s} 1}$ & 7121 & 31341 & 20354 & 6455 & 9271 & 27020 & 16917 & 6682 \\
\hline$\alpha_{\mathrm{s} 0}$ & 1880 & 9140 & 6587 & 2192 & 2282 & 11235 & 5695 & 2783 \\
\hline$\kappa$ & 453 & 5900 & 2518 & 1988 & 421 & 6280 & 2210 & 1972 \\
\hline$\beta \mathrm{B}$ & 588 & 7269 & 1960 & 1804 & 680 & 7656 & 2252 & 2131 \\
\hline$\beta \mathrm{A}_{1}$ & 3408 & 16872 & 11165 & 4127 & 980 & 18000 & 8109 & 5347 \\
\hline$\beta \mathrm{A}_{2}$ & 5837 & 34282 & 18613 & 7557 & 7414 & 25359 & 14840 & 7223 \\
\hline
\end{tabular}


Table 2. Statistical descriptors for NIR calibrations for the prediction of casein fractions content (expressed as normalised area) in reconstituted samples.

\begin{tabular}{|c|c|c|c|c|c|c|c|c|c|c|c|}
\hline Instrument & $\begin{array}{l}\text { Spectral } \\
\text { range }\end{array}$ & Variable & LV & $R^{2}$ & $r^{2}$ & RMSEP & Preprocessing & $C V \%_{\text {REF }}$ & $C V \%_{\text {NIR }}$ & $R E R$ & $R P D$ \\
\hline \multirow{7}{*}{$\begin{array}{l}\text { FT NIR } \\
\text { transflectance }\end{array}$} & \multirow[t]{7}{*}{$1112-2500 \mathrm{~nm}$} & $\alpha_{s 2}$ & & poor & poor & - & - & $9.6-14.9$ & - & - & - \\
\hline & & $\alpha_{\mathrm{s} 1}$ & 4 & 0.85 & 0.87 & 2123 & SNV+SG (15) & 5.7-12.1 & 10.8 & 10.8 & 3.2 \\
\hline & & $\alpha_{\mathrm{s} 0}$ & 2 & 0.83 & 0.80 & 1055 & $S N V+S G(21)$ & $5.5-13.2$ & 16.1 & 6.8 & 2.6 \\
\hline & & $\kappa$ & 8 & 0.998 & 0.71 & 1199 & SNV+SG (15) & $9.6-30.4$ & 49.5 & 4.8 & 1.7 \\
\hline & & $\beta b$ & & poor & poor & - & - & $6.3-14.1$ & - & - & - \\
\hline & & $\beta \mathrm{A}_{1}$ & 2 & 0.98 & 0.83 & 2261 & $S N V+S G(21)$ & $9.1-22.9$ & 20.3 & 6.9 & 2.3 \\
\hline & & $\beta \mathrm{A}_{2}$ & & poor & poor & - & - & $5.2-12.3$ & - & - & - \\
\hline \multirow{7}{*}{$\begin{array}{l}\text { NIR monochromator } \\
\text { transflectance }\end{array}$} & \multirow[t]{7}{*}{$400-2500 \mathrm{~nm}$} & $\alpha_{\mathrm{s} 2}$ & 6 & poor & poor & - & - & $9.6-14.9$ & - & - & - \\
\hline & & $\alpha_{s 1}$ & 3 & 0.79 & 0.83 & 2505 & SG (5) & $5.7-12.1$ & 12.3 & 9.7 & 2.7 \\
\hline & & $\alpha_{\mathrm{s} 0}$ & 3 & 0.77 & 0.77 & 1261 & SNV+SG (5) & $5.5-13.2$ & 18.9 & 7.4 & 2.2 \\
\hline & & $\kappa$ & 7 & 0.93 & 0.64 & 1262 & SNV & $9.6-30.4$ & 49.0 & 4.6 & 1.6 \\
\hline & & $\beta b$ & & poor & poor & - & - & $6.3-14.1$ & - & - & - \\
\hline & & $\beta \mathrm{A}_{1}$ & 7 & 0.84 & 0.84 & 2262 & $M C+S N V$ & $9.1-22.9$ & 22.2 & 7.5 & 2.4 \\
\hline & & $\beta \mathrm{A}_{2}$ & 2 & 0.80 & 0.73 & 2427 & SNV+SG (5) & $5.2-12.3$ & 13.6 & 11.7 & 3.0 \\
\hline \multirow{7}{*}{$\begin{array}{l}\text { NIR monochromator } \\
\text { reflectance }\end{array}$} & \multirow[t]{7}{*}{$400-2500 \mathrm{~nm}$} & $\alpha_{s 2}$ & & poor & poor & - & - & $9.6-14.9$ & - & - & - \\
\hline & & $\alpha_{s 1}$ & 3 & 0.82 & 0.87 & 1868 & $M C+S N V$ & $5.7-12.1$ & 9.9 & 13 & 3.6 \\
\hline & & $\alpha_{s 0}$ & 3 & 0.88 & 0.88 & 679 & SNV+SG (5) & $5.5-13.2$ & 11.0 & 13.8 & 4.1 \\
\hline & & $\kappa$ & 5 & 0.90 & 0.80 & 760 & SNV & $9.6-30.4$ & 31.6 & 7.7 & 2.6 \\
\hline & & $\beta b$ & 9 & 0.98 & 0.80 & 716 & SNV+SG (5) & $6.3-14.1$ & 34.6 & 9.9 & 3.0 \\
\hline & & $\beta \mathrm{A}_{1}$ & 4 & 0.77 & 0.83 & 2148 & SNV+SG (5) & $9.1-22.9$ & 22.96 & 7.9 & 2.5 \\
\hline & & $\beta \mathrm{A}_{2}$ & 6 & 0.90 & 0.94 & 1705 & $M C+S N V$ & $5.2-12.3$ & 9.5 & 16.7 & 4.2 \\
\hline
\end{tabular}

LV: latent variables used; $R^{2}, r^{2}$ coefficient of determination of the calibration model and validation equation respectively; $R M S E P$ : root mean Square error of performance; MC: mean centre; SG: Savitzky-Golay smoothing (number of point smoothed); SNV: standard normal variate; CV: Coefficient of variation; RER: ratio error range; $R P D$ : ratio performance in deviation

statistical parameters of the best models obtained, in terms of the number of latent variables (LVs) used; coefficient of determination in calibration $\left(R^{2}\right)$ and for the samples in the independent validation $\left(r^{2}\right)$; root mean square of standard error in prediction (RMSEP); coefficient of variation of each variable when the samples were analysed by the reference method $\left(C V \%_{\mathrm{REF}}\right)$; and the NIR calibration model $\left(\mathrm{CV} \%_{\mathrm{NIR}}\right)$; $R E R$ and RPD indexes. The pre-processing procedures applied to spectra (SG: second derivative Savitzky-Golay, polynomial order 2, followed by the number of smoothing points in brackets; SNV: Standard normal variate; and MC: mean centringl are also reported.

The coefficients of variation (CV\%) for each NIR calibration were calculated and compared to those of the electrophoretic reference method. As shown in Table 2, the CV\% associated with reflectance measurements were generally comparable to those associated with electrophoretic analysis, even if slightly higher. Spectra acquired in reflectance mode led, overall, to good predictions, with PLS models using a number of LVs between three and nine. The number of LVs was chosen as proposed by the software. Good results in calibration were obtained for $\beta B$ - and $\beta A 2$-casein and satisfactory performances were found for $\alpha_{s 1^{-}}, \alpha_{s 0^{-}}$and $\kappa$-casein. Good

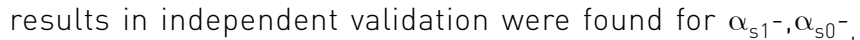
$\beta A 1$ - and $\beta A 2$-casein with $r^{2}$ values of $0.87,0.88,0.83$ and 0.94 respectively as shown in Figures 6(a)-(d). Conversely, the models for $\kappa$ - and $\beta B$-casein showed the poorest performances and it was not possible to build a robust predictive model for the quantification of the $\alpha_{\mathrm{s} 2}$-casein. $\kappa$ - and $\beta \mathrm{B}$-casein also showed the highest $C V \%$ both for NIR and the reference method. The low performance in the quantification of $\kappa$ - and $\alpha_{\mathrm{s} 2}$-casein can be related to their very low concentration and lower variability in comparison to the other fractions. Moreover, the $\alpha_{\mathrm{s} 2}$-casein electrophoretic peak is located in a region where several peaks overlap, which may lead to a difficult individuation and quantification.

The prediction accuracy of each calibration was also evaluated based on the RER and RPDindexes. For $\alpha_{\mathrm{s} 1^{-}}, \mathrm{\alpha}_{\mathrm{s} 0^{-}}$and $\beta A 2$-caseins, 


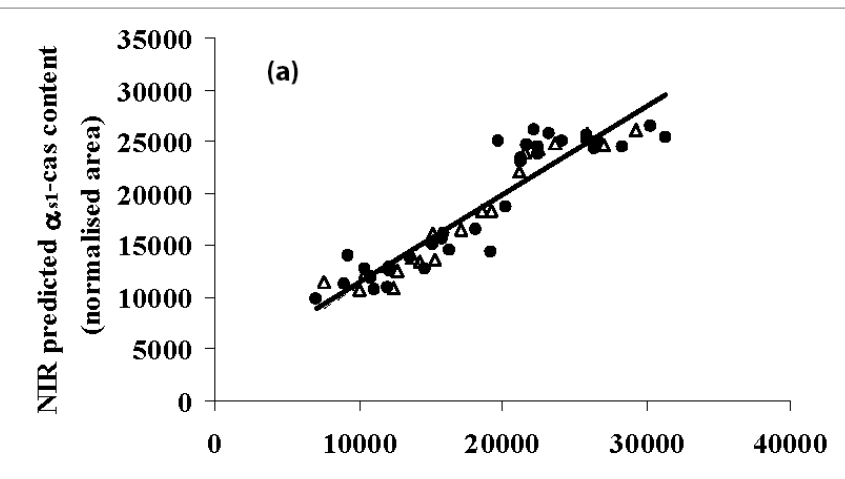

CZE measure $d \alpha_{s 1}$-cas content (normalised area)
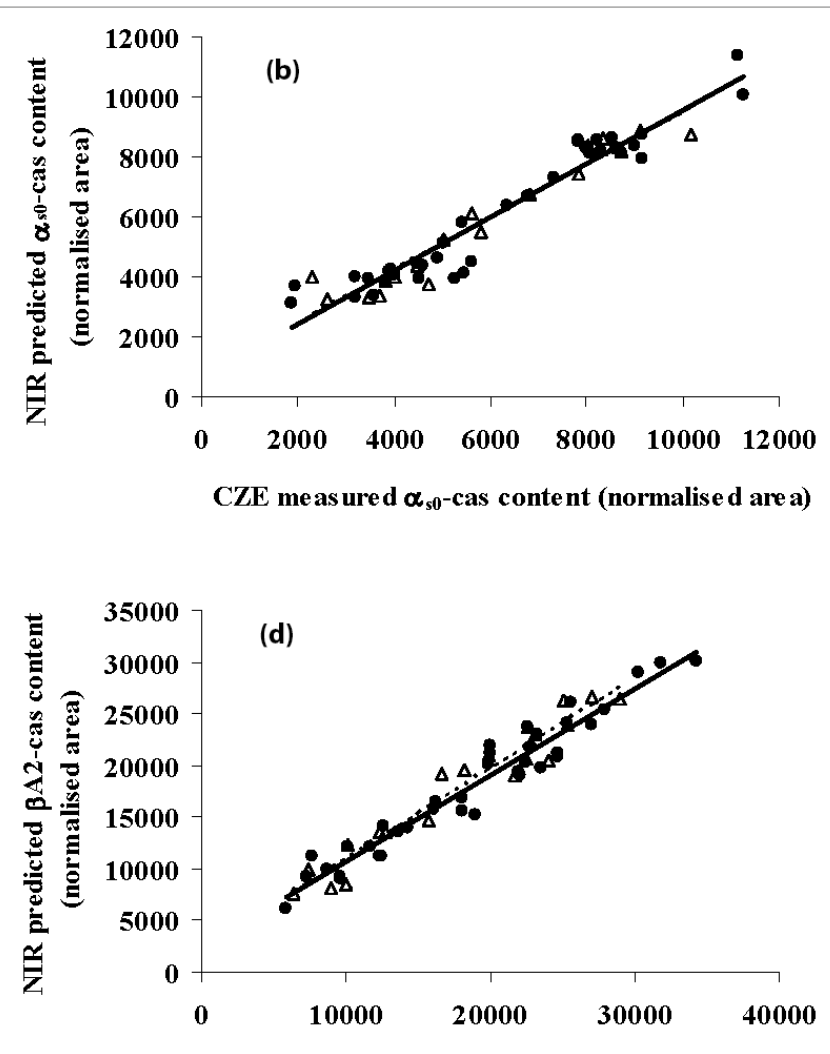

CZE me as ure d $\beta A 2$-cas conte nt (normalised area)

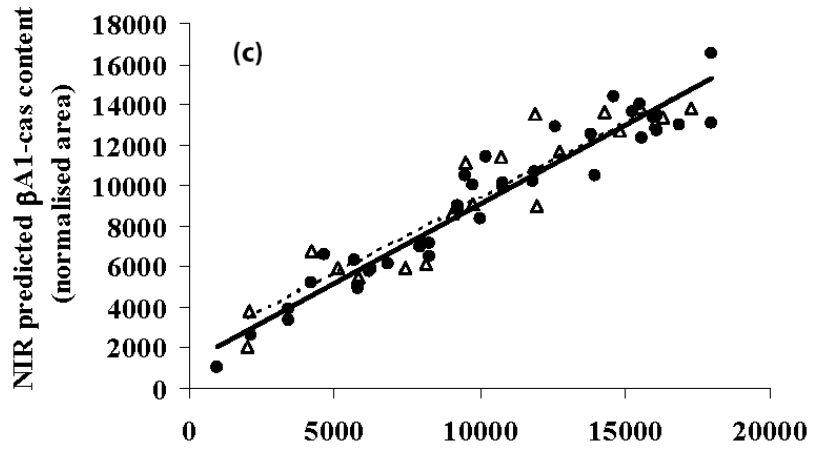

CZE measure d $\mathrm{\beta A1}$-cas content (normalis ed area)

Figure 6. Correlation between measured and predicted NIR values for $\alpha_{s 1}-(a), \alpha_{s 0}-(b), \beta A 1-(c)$ and $\beta A 2$-casein (d) contents: $(\bullet)$ calibration samples; $(\Delta)$ validation samples.

$R E R$ values between 13 and 16.7 and $R P D$ values between 3.6 and 4.2 were obtained. According to the classification proposed by Williams, ${ }^{22}$ such models are considered suitable for a valid screening method. The calculated values (RER 7.7-10; RPD 2.5-3) for $\kappa^{-}, \beta B-$ and $\beta A 1$ caseins indicate less robust models, suitable only for a very rough screening.

In general, as shown in Table 2, good results with the PLS models were obtained after applying different chemometric pre-treatments to the spectral data.

In a previous study carried out on goats' milk, using the system of sample drying on glass fibre filter disk, Diaz et al. ${ }^{25}$ achieved $r^{2}$ values of 0.86 for the prediction of $\alpha_{s \text { - }}$ and $k$-casein and 0.92 for $\beta$-casein. More recently, Cattaneo et al. ${ }^{26}$ tested the ability of FT-NIR to determine $\alpha_{\mathrm{s} 1}$ - and $\beta$-casein in cow milk samples. NIR spectra collected with a transflectance optical probe showed correlation $R^{2}$ values of 0.85 and 0.94 against the reference HPLC data, for $\alpha_{s 1}$ - and $\beta$-casein, respectively; these are close to those found here.

In this work, the good performance obtained in reflectance mode can be attributed to using longer path-lengths compared with those available in transflectance mode. Reflectance spectroscopy does not pose any limitation on the size of the measurement cell, which can be a considerable advantage for on-line measurement of biological fluids ${ }^{27}$ and especially for the on-line determination of casein fractions in milk. Moreover, casein samples are a quite turbid and opaque media with some scattering effects caused by casein micelles, and NIR reflectance spectra showed the interaction between scattering and absorption effect of the sample. ${ }^{18}$ Therefore, the resulting calibrations exploit both the scattering contribution and the real absorptions.

Since the two instruments tested in this study operate in different wavelength ranges, the effect of the spectral region on the calibration models' performances was assessed. Transflectance and reflectance spectra obtained from the NIRSystem 6500 were used to build up new models in the NIR region between $1100 \mathrm{~nm}$ and $2500 \mathrm{~nm}$. These new models showed a general worsening in calibration and validation results, showing that the enlarged vis-NIR spectral region was useful to create good predictive models. Models were also built up using data for the $700 \mathrm{~nm}$ to $1100 \mathrm{~nm}$ region from spectra acquired in reflectance and transflectance mode with the NIRSystem 6500. The results obtained were comparable with those of the entire range $(400-2500 \mathrm{~nm})$. Table 3 summarises the PLS results in the three spectral ranges $(400-2500 \mathrm{~nm}$; $700-1100 \mathrm{~nm}$; $1100-2500 \mathrm{~nm}$ ) obtained with spectra acquired in reflectance mode. Concerning the transflectance mode, the calibration models did not perform satisfactorily (data not shown). Almost all the NIR experiments of milk were made for the $1100-2500 \mathrm{~nm}$ region. Among the investigations 
Table 3. Comparison of calibrations obtained with NIR monochromator spectra recorded in reflectance mode in different wavelength regions.

\begin{tabular}{|c|c|c|c|c|c|}
\hline Spectral range & Variable & LV & $r^{2}$ & $\begin{array}{c}\text { RMSEP } \\
\text { (normalised area) }\end{array}$ & Pre-processing \\
\hline \multirow[t]{4}{*}{$400-2500 \mathrm{~nm}$} & $\alpha_{s 1}$ & 3 & 0.86 & 1868 & $M C$ \\
\hline & $\alpha_{\mathrm{s} 0}$ & 3 & 0.88 & 679 & SG (5) \\
\hline & $\beta \mathrm{A}_{1}$ & 4 & 0.83 & 2148 & $M C$ \\
\hline & $\beta A_{2}$ & 6 & 0.94 & 1705 & $\mathrm{MC}+\mathrm{SNV}$ \\
\hline \multirow[t]{4}{*}{$700-1100 \mathrm{~nm}$} & $\alpha_{s 1}$ & 3 & 0.86 & 1774 & SG (5) \\
\hline & $\alpha_{\mathrm{s} 0}$ & 3 & 0.83 & 945 & $S N V+S G(5)$ \\
\hline & $\beta \mathrm{A}_{1}$ & 3 & 0.80 & 2166 & $\mathrm{MC}+\mathrm{SNV}$ \\
\hline & $\beta A_{2}$ & 4 & 0.87 & 1807 & $S N V+S G(5)$ \\
\hline \multirow[t]{4}{*}{$1100-2500 \mathrm{~nm}$} & $\alpha_{s 1}$ & 4 & 0.74 & 1922 & $\mathrm{MC}+\mathrm{SNV}$ \\
\hline & $\alpha_{\mathrm{s} 0}$ & 4 & 0.80 & 889 & SG (5) \\
\hline & $\beta \mathrm{A}_{1}$ & 5 & 0.68 & 2201 & SG (5) \\
\hline & $\beta A_{2}$ & 6 & 0.81 & 1824 & SG (5) \\
\hline
\end{tabular}

See Table 2 for abbreviations

that consider the potential of the short-wave NIR region for quantitative analysis of milk composition, some have conflicting results. ${ }^{24-29}$ Tsenkova et al. ${ }^{24}$ found satisfactory accuracy for the determination of total protein content in the vis-NIR region, from $700 \mathrm{~nm}$ to $1100 \mathrm{~nm}$, when a $1 \mathrm{~mm}$ sample thickness was used. They obtained $R^{2}=0.63$ and SECV $=0.13 w t \%$ when the first derivative was applied as the spectra pre-treatment. Šašić and Ozaki ${ }^{28}$ reported reliable results for PLS calibration of proteins in milk using the short-wave NIR region. The paper reports a calibration model with a coefficient of determination of $R^{2}=0.90$ and $R M S E C V=0.13 w t \%$. However, more recently Aernout et al. ${ }^{29}$ published a work in which different wavelength ranges were evaluated as a factor influencing the accuracy for predicting the different milk components. They found NIR (1000-2500 nm) transmittance measurements the best option to use to predict the composition of milk, while the short wavelength range was found not to be sufficient for accurate monitoring of the composition of milk.

This aspect warrants further investigation since the possibility of using short wave NIR in milk composition monitoring is of larger practical interest; the high transmittance of light and the availability of excellent and cheap detectors make it suitable for the construction of on-line sensors. ${ }^{28}$

\section{Conclusions}

The results of this study demonstrate that NIR spectroscopy is a useful technique for the determination and quantification of casein fractions $\left(\alpha_{\mathrm{s} 0^{-}}, \alpha_{\mathrm{s} 1^{-}}, \alpha_{\mathrm{s} 2^{-}}, \kappa\right.$-casein) and genetic variants ( $\beta B$ - $\beta A 1-, \beta A 2$-casein) in an aqueous simplified model. Among the different sample presentation modes, reflectance measurements gave the best results for quantification of all casein fractions, but not for $\alpha_{\mathrm{s} 2}$-casein. The lower accuracy compared with the reference method is compensated for by the possibility of a massive use of NIR thanks to the low cost and rapidity of analyses, even if a sample preparation step is required. The spectral region was found to be a significant factor for good predictions; best results were obtained using vis/NIR range (400-2500 $\mathrm{nm})$.

The results are encouraging, but there is a need to test the potential of NIR spectroscopy on milk samples and to use samples which bring new sources of variability. Aspects such as breed, season and animal feeding should be considered. Good performances on real samples could be exploited for a milk selection for its final purpose and NIR technology can be used for constant monitoring of the variability of milk proteins, in order to reduce the presence of genetic variants unfavourable for the cheese-making process or to select milk free of certain casein variants for the production of milk with particular nutritional qualities.

\section{Acknowledgement}

This research was funded by Ministry of Agricultural Food and Forestry Policies within the project RiProSel, subproject CHEESE for the years 2009-2012.

\section{References}

1. P.F. Fox, "Milk proteins: general and historical aspects", in Advanced Dairy Chemistry: Volume 1-Proteins, Ed by 
P.F. Fox and P.L.H. McSweeney. Springer, New York, USA (2003). doi: $\underline{10.1007 / 978-1-4419-8602-3}$

2. T.P. Guinee and B. O'Brien, "The quality of milk for cheese manufacture", in Technology of Cheesemaking, Ed by B.A. Law and A. Tamime. John Wiley \& Sons, Ltd, Chichester, West Sussex, UK, pp. 19-22 (2010). doi: 10.1002/9781444323740.ch1

3. A. Comin, M. Cassandro, S. Chessa, M. Ojala, R. Dal Zotto, M. De Marchi, P. Carnier, L. Gallo, G. Pagnacco and G. Bittante, "Effects of composite $\beta$ - and $\kappa$-casein genotypes on milk coagulation, quality, and yield traits in Italian holstein cows", J. Dairy Sci. 91(10), 4022 (2008) doi: 10.3168/jds.2007-0546

4. V.V. Mistry, "Chymosin in cheese making", in Food Biochemistry and Food Processing, Ed by Y.H. Hui, W. Nip, L.M.L. Nollet, G. Paliyath and B.K. Simpson. John Wiley \& Sons Ltd, Chichester, West Sussex, UK, pp. 228-229 (2008).

5. J.M. Heck, A. Schennink, H.J. van Valenberg, H. Bovenhuis, M.H. Visker, J.A. van Arendonk and A.C. van Hooijdonk, "Effects of milk protein variants on the protein composition of bovine milk", J. Dairy Sci. 92(3), 1192 (2009). doi: $\underline{10.3168 / j \mathrm{jds} .2008-1208}$

6. A.M. Caroli, S. Chessa and G.J. Erhardt, "Invited review: Milk protein polymorphisms in cattle: effect on animal breeding and human nutrition", J. Dairy Sci. 92(11), 5335 (2009). doi: 10.3168/jds.2009-2461

7. H.M. Farrel, R. Jimenez-Flores, G.T. Bleck, E.M. Brown, J.E. Butler, L.K. Creamer, C.L. Hicks, C.M. Hollar, K.F. $\mathrm{Ng}$-Kwai-Hang and H.E. Swaisgood, "Nomenclature of the proteins of cows' milk-sixth revision", J. Dairy Sci. 87(6), 1641 (2004). doi: 10.3168/jds.S00220302(04)73319-6

8. EFSA, "Opinion of the Scientific Panel on Dietetic Products, Nutrition and Allergies on a request from the Commission relating to the evaluation of allergenic foods for labeling purposes", EFSA J. 2, 32 (2004).

9. H. Korhonen and A. Pihlanto, "Bioactive peptides: Production and functionality", Int. Dairy J. 16(9), 945 (2006). doi: 10.1016/j.idairyj.2005.10.012

10. S. Bouhallab and D. Bouglé, "Biopeptides of milk: caseinophosphopeptides and mineral bioavailability", Reprod. Nutr. Dev. 44(5), 493 (2004). doi: $10.1051 /$ rnd:2004053

11. Y.W. Park, Bioactive Components in Milk and Dairy Products. John Wiley \& Sons Ltd, Chichester, West Sussex, UK (2009). doi: 10.1002/9780813821504

12. R. Tsenkova, S. Atanassova, K. Itoh, Y. Ozaki and K. Toyoda, "Near infrared spectroscopy for biomonitoring: cow milk composition measurement in a spectral region from 1,100 to 2,400 nanometers", J. Anim. Sci. 78(3), 515 (2000).

13. R. Jankovská and K. Šustová, "Analysis of cow milk by near-infrared spectroscopy”, Czech J. Food Sci. 21(4), 123 (2003).

14. H. Kamishikiryo-Yamashita, Y. Oritani, H. Takamura and T. Matoba, "Protein content in milk by near-infrared spectroscopy", J. Food Sci. 59(2), 313 (1994). doi: $10.1111 /$ j.1365-2621.1994.tb06956.x

15. M.F. Laporte and P. Paquin, "Near-Infrared analysis of fat, protein, and casein in cow's milk", J. Agric. Food Chem. 47(7), 2600 (1999). doi: 10.1021/jf980929r

16. K. Šustova, J. Rưžičkova and J. Kuchtik, "Application of FT near spectroscopy for determination of true protein and casein in milk", Czech J. Anim. Sci. 52(9), 284 (2007).

17. D.A. Burns and E.W. Ciurczak (Eds), Handbook of NearInfrared Analysis. Marcel Dekker, Inc., New York, USA (2001).

18. P. Williams and K. Norris (Eds), Near-Infrared Technology in the Agricultural and Food Industries. American Association of Cereal Chemists Inc., St Paul, Minnesota, USA (2001).

19. Standard ISO 17997-1:2004 (IDF 29-1: 2004) MilkDetermination of casein-nitrogen content: Part 1: Indirect method (Reference method).

20. Standard ISO 8968-1:2001 (IDF 20-1: 2001) MilkDetermination of nitrogen content: Part 1: Kjeldahl method.

21. I. Recio and C. Olieman, "Determination of denatured serum proteins in the casein fraction of heat-treated milk by capillary zone electrophoresis", Electrophoresis 17(7), 1228 (1996). doi: 10.1002/elps.1150170710

22. P. Williams, Near-infrared Technology-Getting the Best Out of Light. PDK Grain. Nanaimo, Canada. (2003).

23. I. Recio, L. Amigo, M. Ramos and R. López-Fandiño, "Application of capillary electrophoresis to the study of proteolysis of caseins", J. Dairy Res. 64(2), 221 (1997). doi: $10.1017 /$ S0022029996002087

24. R. Tsenkova, S. Atanassova, K. Toyoda, Y. Ozaki, K. Itoh and T. Fearn, "Near infrared spectroscopy for dairy management: measurement of unhomogenized milk composition", J. Dairy Sci. 82(11), 2344 (1999). doi: 10.3168/jds.S0022-0302(99)75484-6

25. E. Díaz-Carrillo, A. Muñoz-Serrano, A. AlonsoMoraga and J.M. Serradilla-Manrique, "Near infrared calibrations for goat's milk components: protein, total casein, $\alpha_{s}{ }^{-}, \beta-$ and $\kappa$-caseins, fat and lactose", J. Near Infrared Spectrosc. 1(3), 141 (1993). doi: 10.1255/jnirs.17

26. T.M.P. Cattaneo, M. Feligini, I. Bonizzi, R. Giangiacomo and S. Barzaghi, "Testing the ability of FT-NIR to determine the $\alpha_{s 1}$-casein and $\beta$-casein content in individual milk samples", Proceedings of the $14^{\text {th }}$ International Conference on NIR Spectroscopy, Bangkok, Thailand 9-13 November 2009, Ed. By S. Saranwong, S. Kasemsumran, W. Thanapase and P. Williams. IM Publications, Chichester, UK (2009).

27. W. Saeys, A.M. Mouazen and H. Ramon, "Potential for on-site and on-line analysis of pig manure using visual and near-infrared reflectance spectroscopy", Biosystems Eng. 91(4), 393 (2005). doi: 10.1016/j.biosystemseng.2005.05.001

28. S. Šašić and Y. Ozaki, "Short-wave near-infrared spectroscopy of biological fluids. 1. Quantitative analysis of fat, protein, and lactose in raw milk by 
partial least-squares regression and band assignment", Anal. Chem. 73(1), 64 (2001). doi: 10.1021/ac000469c

29. B. Aernouts, E. Polshin, J. Lammertyn and W. Saeys, "Visible and near-infrared spectroscopic analysis of raw milk for cow health monitoring: Reflectance or transmittance?", J. Dairy Sci. 94(11), 5315 (2011). doi: 10.3168/ ids.2011-4354 